\title{
Detection of Possible Thunderstorm Formation Inferred from Weather Element Changes at Ground Level on a Mountain Slope
}

\author{
R. Vishnu*, S. Murali Das, S. Sampath ${ }^{\#}$ and G. Mohan Kumar
}

Centre for Earth Science Studies, Akkulam, Thiruvananthapuram, India

\begin{abstract}
In India, Kerala state is known to have relatively high lightning incidence. The nature of spatial and temporal distribution of past incidents, type of thunderclouds which cause lightning, the topography, proximity to a mountain range and sea point to the possibility of the mountain weather aiding in $\mathrm{Cb}$ formation. For investigating the role of mountain weather in convective $\mathrm{Cb}$ formation a field station consisting of an automatic weather station and a lightning detector was established on the slope of the nearby Western Ghats mountain range. On thunderstorm days the mountain weather data show specific reduction in air temperature with synchronized increase in relative humidity along with a reduction in pressure of the order of $0.5 \mathrm{hPa}$ between 10:00 $\mathrm{h}$ and 18:00 h. The variations in data are indicative of a strong updraft. The lightning detector showed thunderstorm activity, aligned with the direction of the mountain range, about an hour after detecting the changes in weather elements. Water vapour for thunderstorm formation seems to come from the nearby sea as indicated by the wind data. Data collected for three years show that existence of strong updrafts seem to be a characteristic of the mountain weather during thunderstorm months. Data from a coastal station located $40 \mathrm{~km}$ south west of the mountain station do not indicate updrafts either on the thunderstorm days or otherwise. As updrafts can lead to $\mathrm{Cb}$ formation monitoring weather elements as discussed here is useful for detecting thunderstorms at the developing stage itself.
\end{abstract}

Keywords: Convective $\mathrm{Cb}$, thunderstorm, mountain weather, lightning, updraft.

\section{INTRODUCTION}

Combined Lightning Image Sensor (LIS) and Optical Transient Detector (OTD) images from satellites [1] show that, Kerala a state in India, has relatively high lightning incidence in the country. Results of a study based on reported incidents of lightning from 1986 to 2002 in Kerala show that on an average 57 people die and 83 people are injured in the state annually [2]. The spatial distribution of lightning incidents in Kerala is given in Murali Das et al. [3]. However the cause of this relatively high lightning incidence is not known. The state is located on the southern end of the Indian peninsula and lies in a south-east, north-west direction. It has a length of about $550 \mathrm{~km}$ and a maximum width of only $120 \mathrm{~km}$. The state is bounded on the western side by the Arabian Sea and on the eastern side by the Western Ghats mountain range. The Indian Ocean is on the southern side of the state. Considering the distribution of lightning events, the proximity of mountains and other relevant factors, the characteristics of lightning incidence in Kerala are deduced as follows:

1. Most of the lightning incidents in Kerala are caused by convective thunderclouds. This is inferred from Murali Das et al. [3] where it is reported that most of the lightning incidents here occur in the evenings between 15:00 $\mathrm{h}$ and 19:00 $\mathrm{h}$ local time.

*Address correspondence to this author at the Centre for Earth Science Studies, Akkulam, Thiruvananthapuram, India; Tel: +91-9847194729, +91471-2511642; Fax: +91-471-2442280; E-mail: vishnurnair@yahoo.com

"Retired, present address: D227, Swathi Nagar, Thiruvananthapuram- 695023, India
Cumulonimbus cloud $(\mathrm{Cb})$ occurrence data of India Meteorology Department also corroborate this observation $[2,3]$.

2. Kerala, the region west of the mountains has high lightning incidence where as the regions on the eastern side of the same mountains has less lightning [1]. Mountain tops in Kerala also have lesser lightning incidence $[2,3]$.

3. It is known that mountain weather is conducive for formation of Cbs $[4,5]$. Palakkad gap is a break in the mountain range near the middle of the state and to the west of it lightning incidence is relatively very less [2, $3]$. This aspect has to be seen in conjunction with the fact that during the months of most lightning occurrence in Kerala namely April, May, October and November [3] the predominant wind direction is north-east. Possibly the convective Cbs form on the western side of the mountain and upon formation move towards south - west to cause lightning in the regions west of the mountains. Palakkad gap has no mountain and so Cbs do not form resulting in fewer incidents to the west of it.

4. The large scale system of south-west monsoon is active in the region from June to September and lightning incidence during this period is few [3]. The significance is that possibly charged convective Cbs do not form when a bigger system is present.

Hence, the spatial and temporal distribution of lightning incidence, considered in conjunction with the topography of the state leads to the hypothesis that the mountains of the Western Ghats could be instrumental in forming convective 
Cbs. The convective Cbs formed due to conducive weather on the western side of the mountain seem to be responsible for causing relatively high lightning incidence in Kerala. To experimentally establish the role of mountain weather near Western Ghats in forming $\mathrm{Cbs}$ an investigation was conducted. Results of the investigation are presented and discussed.

\section{THE EXPERIMENTAL SET UP}

A field station was established at Braemore (Lat.: $8^{\circ} 45^{\prime} \mathrm{N}$, Long.: $77^{\circ} 5^{\prime} \mathrm{E}$ ) near Nedumangad in Thiruvananthapuram District. This district is the southernmost one in Kerala. The field station was on the western slope of the mountains. The station was established on the mountain slope because of the possibility of instability occurrence on the slopes [6] and the station on the slope may detect finer level changes in weather parameters during possible instability occurrence.

For the Cbs that produce lightning in Kerala, the large water vapour requirement seems to be met from the Arabian Sea or the Indian Ocean or both. The location Braemore, is at an approximate altitude of $400 \mathrm{~m}$ above mean sea level (AMSL) and at a radial distance of about $40 \mathrm{~km}$ from the west coast. Shown in Fig. (1) is a map of the location of the Braemore station. From the height references it can be seen that the station is on the western slope of the Western Ghats mountain range. Agastya Malai, one of the highest spots of the mountain range, with a spot height of $1869 \mathrm{~m}$ can be seen marked on the map. Physiography map of Kerala and location of the state of Kerala in south India are also shown separately in the figure.

The field station had two types of equipment. One was an automatic weather station and the other, an instrument for locating lightning discharges. The weather parameters monitored were air temperature (AT), atmospheric pressure $(\mathrm{P})$, relative humidity $(\mathrm{RH})$, wind direction (WD), wind speed (WS), rain fall (RF) and sun duration (SD). Table 1 gives the weather elements monitored, type of sensors, their output sensitivity/resolution and range of measurements.

The weather parameter data were stored in a data logger. The data acquisition rate could be programmed in the data logger. For the present study the data logger was programmed for collecting data every 10 minutes. Each sample taken at 10 minutes interval is an average of all samples taken at 10 seconds interval. The data stored in the memory of the data logger were transferred every week to a computer. The 10 minutes rate of data acquisition was selected as the phenomenon to be studied has a time scale of the order of an hour [8]. The second equipment namely the lightning detection receiver, manufactured by $\mathrm{M} / \mathrm{s}$ Boltek, USA has a direction finding crossed loop antenna which

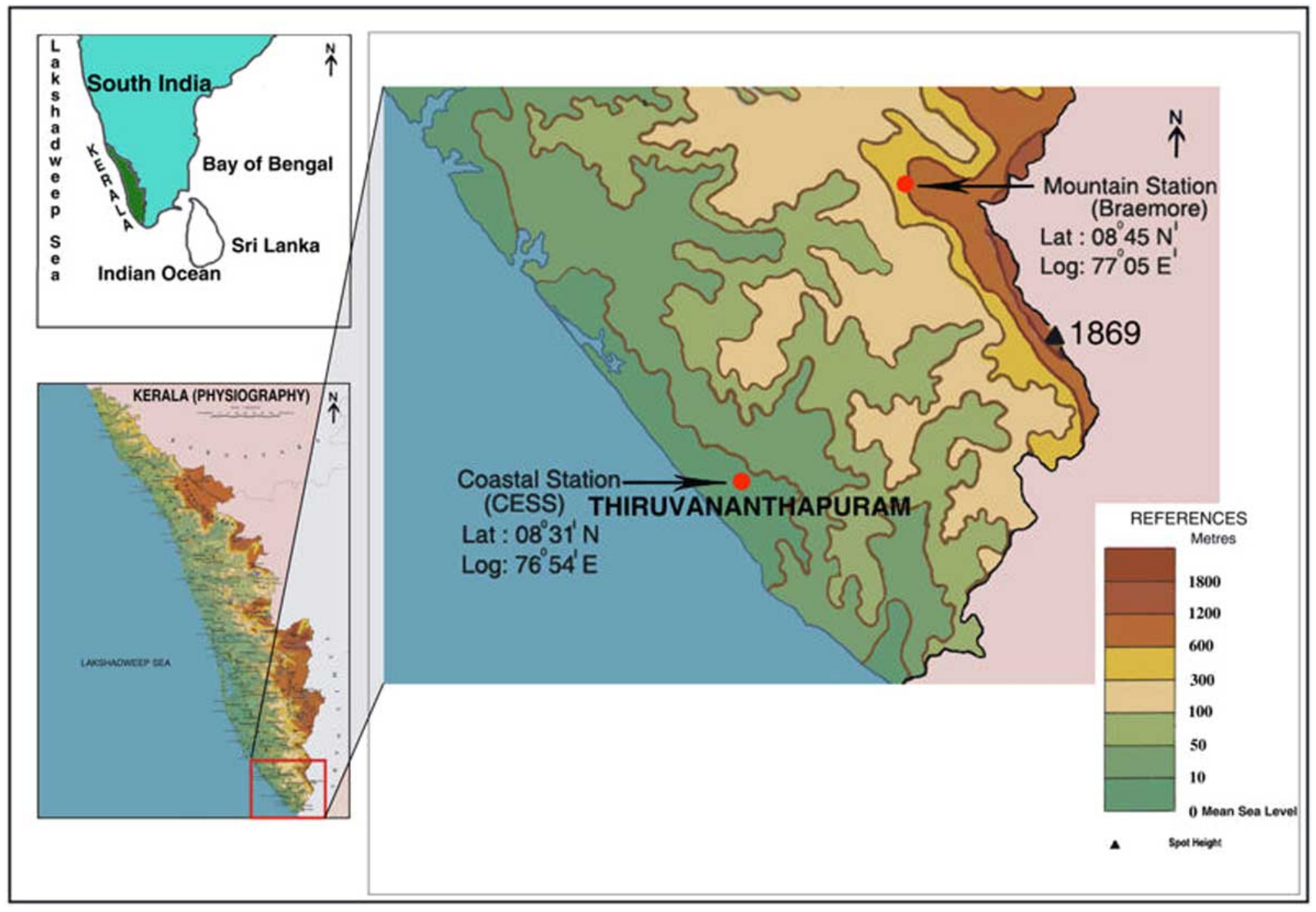

Fig. (1). Map showing the location of the mountain station at Braemore [7]. Location of a coastal station at Thiruvananthapuram (CESS) which is mentioned later in the paper is also shown. 
Table 1. Specifications of Sensors Used for Measurement of Weather Elements

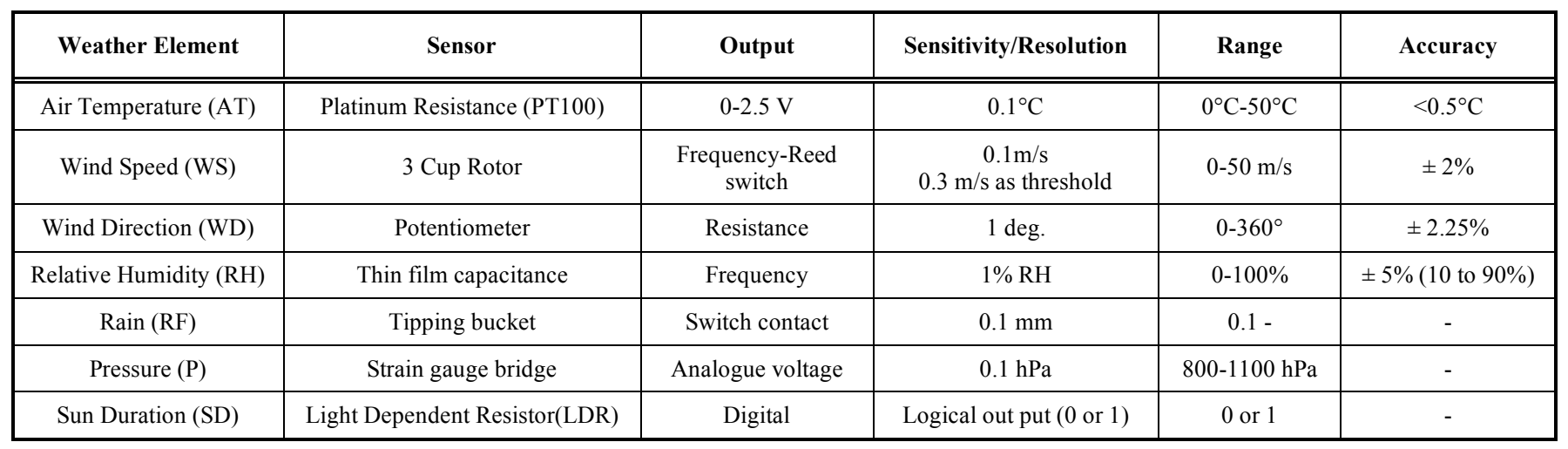

detects the location of the discharge. The receiver estimates distance of lightning discharge location from received signal strength using a software and displays on a computer screen. There are three circles in the display at 160,320 and $480 \mathrm{~km}$ (or 100, 200 and 300 miles) indicating radial distance of the discharge from the antenna location. The range and number of circles in the display can be changed. For example the range of circles shown in a display later in this paper has a range of $100 \mathrm{~km}$ and has four circles at every $25 \mathrm{~km}$. The time variation of spatial distribution of thunderstorm activity is stored in a computer on a daily basis. However the stored data do not provide the attributes of the discharges. The recorded data provides a slide show of lightning distribution with time. This display gives the direction of propagation and spatial distribution of lightning discharges with advance of slide show, for each day. In addition to the records of the lightning detector thunderstorm days were noted by personal observation also.

\section{RESULTS AND ANALYSIS}

\subsection{Significant Aspects}

Data were collected from the station for a period of more than three years. The station being in a location of lightning activity the data gaps brought about due to equipment failure by lightning hit was frequent.

The data were analysed for local time variations only. Hence all the data presented in this paper are in local time, namely the Indian Standard Time which leads the Greenwich Mean Time by 5 hours and 30 minutes.

The data collected were screened and evaluated for fine variations in all the weather elements monitored. The intention was to detect changes in the data corresponding to an instability, updraft or relatively fast increase in RH. It is known that lifting of moist air due to orographic irregularities can result in cloud formation [6]. The present weather station location is on the slope of Western Ghats mountains and this is a place where orographic lifting can occur. This is because the slope increases gradually in the direction of wind from $5^{\circ}$ to the horizontal at $20 \mathrm{~km}$ inside coast to $30^{\circ}$ to horizontal at $45 \mathrm{~km}$ [7]. At $45 \mathrm{~km}$ inside the coast the altitude increases to $300 \mathrm{~m}$. As will be seen later from the data both at the coast and at Braemore the wind direction during day time is about $250^{\circ}$, which is perpendicular to the mountain range. It seems the orographic lifting specified in Houze Jr. [6] possibly is related to this mountain range as this is the prominent mountain range well known to influence rain in India. A station like the present one located in a region where clouds can form may detect changes in the weather elements as sample of an updraft. The updraft may cover a large area. Another important characteristic of the station location is that it is situated at about $400 \mathrm{~m}$ AMSL. Because of the altitude, the station location will most probably be included in an updraft occurring in the region and so the weather elements monitored at the station can reflect the changes corresponding to instability. This instability may lead to cumulus and some times cumulonimbus cloud formation. The data acquired and analysed here show that changes in weather elements monitored by the weather station at the mountain slope can be a sign of an updraft which is an indicator of instability.

\subsection{Validation of the Weather Station}

Since finer level changes in weather elements at surface corresponding to instability or cloud formation has not been reported it is necessary to validate the weather station for it's capability to detect such events. In other words the data collected from the weather station should be evaluated first to find variations corresponding to a known weather phenomenon. The data collected on 14/03/05 detected such a known weather phenomenon rather clearly. The phenomenon detected is atmosphere effect. Atmosphere effect is a well known phenomenon [9] caused by presence of cloud overhead. The cloud cover impedes vertical circulation which results in rise of air temperature and consequent decrease in humidity at the surface. The data of the day are shown in Fig. (2).

There was rain fall before $04: 00 \mathrm{~h}$ on this day which is indicative of the presence of cloud overhead. P and AT showed an increase near this time along with a decrease in RH. Normally AT doesn't increase before sunrise. The changes seen in the weather elements and shown in Fig. (2) have happened well before sun rise. The sun rise at the location as detected by the solar sensor was at 06:37 h. The data show that the changes in the three weather parameters have happened at the same time and for the same duration. The overhead cloud seems to have impeded the vertical circulation leading to an increase in P. The AT increase and $\mathrm{RH}$ decrease are caused by the increase in P. Hence the data show that the weather station can detect such phenomenon 

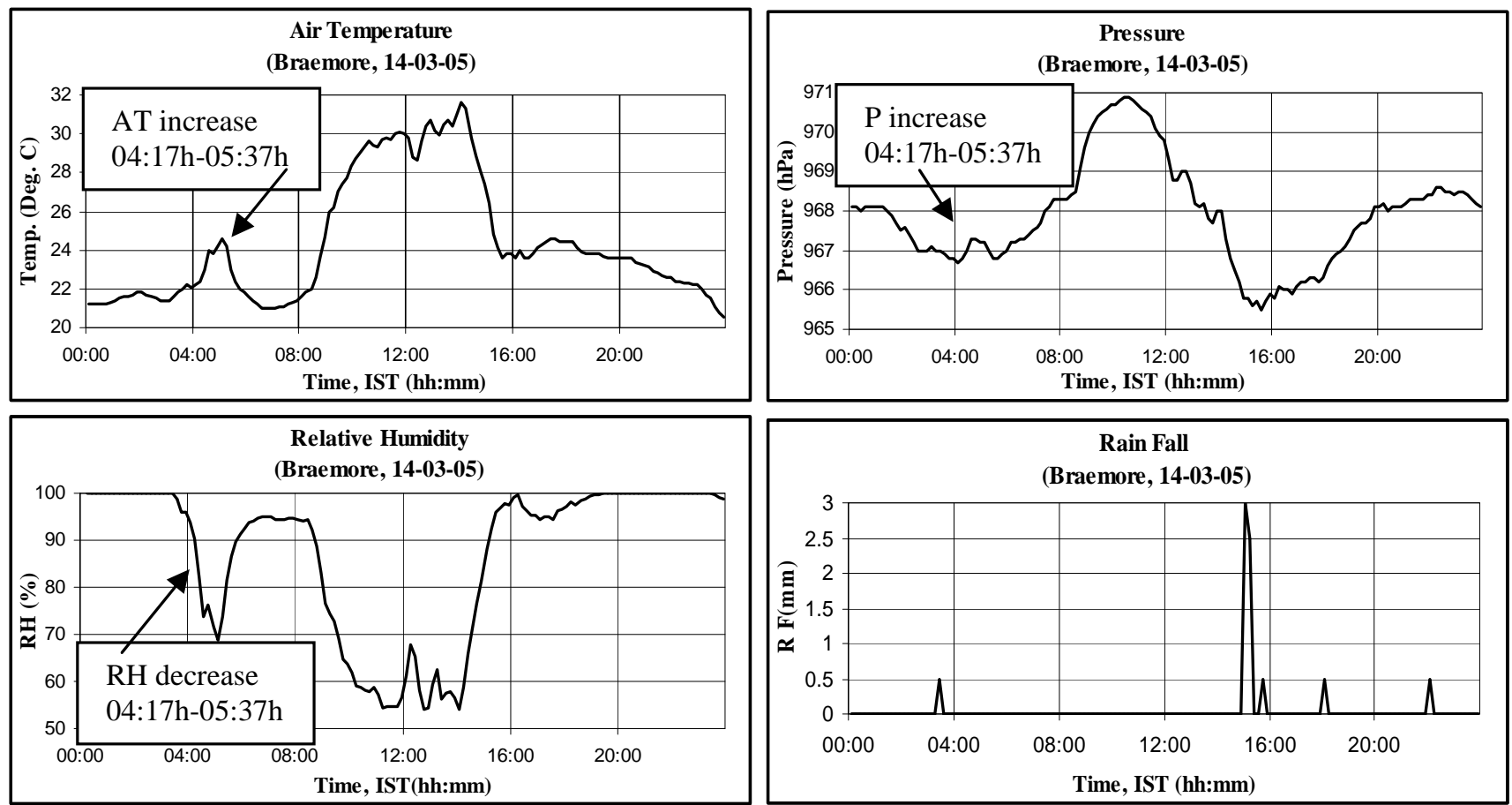

Fig. (2). Data on four weather elements from Braemore for 24 hours on 14/03/05 showing occurrence of atmosphere effect between 04:17 h and 05:37 h.

where a change in pressure and consequent changes in AT and $\mathrm{RH}$ etc. occur.

\subsection{Detection of Updraft from Changes in Weather Elements}

The main aim of the study was to identify ground level changes in weather parameters corresponding to instabilities if any, as instabilities can be taken as an indication of possible thundercloud formation [10]. Cloud formation requires the presence of humidity. Increase in humidity and vertical motion of air may be considered as indications of lifting which can lead to cloud formation as mentioned by Houze Jr. [6]. A change in RH should be seen reflected in an AT change also. Hence, to ascertain the formation of
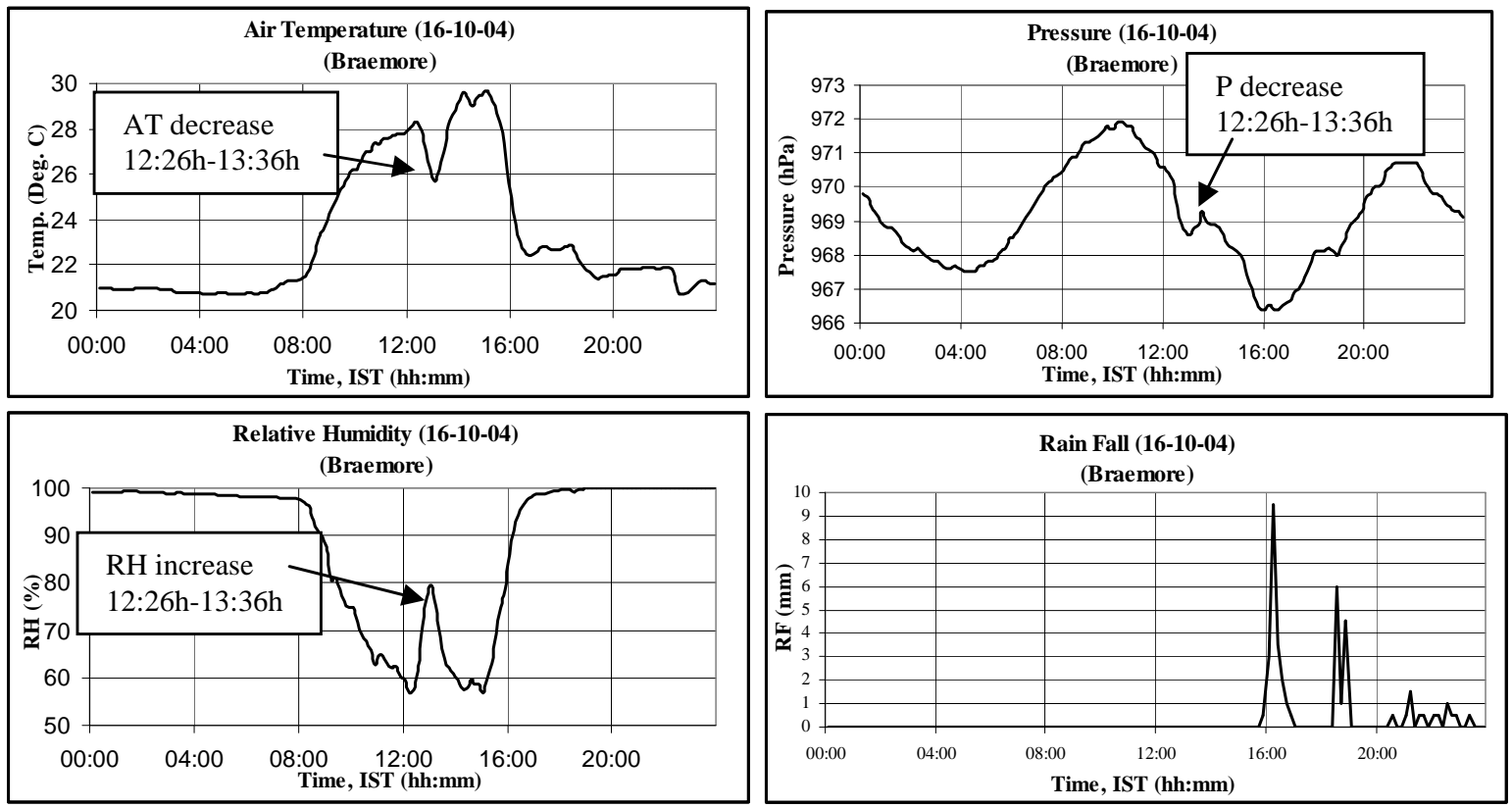

Fig. (3). Variation of weather elements, on a thunderstorm day, indicating an updraft of humid air. 
thunder cloud, interrelated variations between weather parameters on thunder storm days have been examined. Fig. (3) shows the variations of four significant weather elements for 24 hours on 16-10-2004.

AT shows a prominent reduction with a maximum decrease of $2^{\circ} \mathrm{C}$ between $12: 26 \mathrm{~h}$ and 13:36 h. Exactly at same times and for the same duration RH shows an increase with a maximum increase of $20 \%$. At exactly same times and precisely for the same duration the pressure also shows a decrease with a maximum reduction of $0.5 \mathrm{hPa}$.

\subsubsection{Deduction of Causes Behind the Changes in P, AT and $\mathrm{RH}$}

Normally air temperature at a place can decrease during day time due to cooling by rain or by arrival of cold air at the location by vertical or horizontal transport. Rain or horizontal transport of cold air need not cause a decrease in pressure as seen in pressure graph of Fig. (3). In fact, descent of air from upper colder layers of troposphere will involve an increase in pressure [11]. In the present case the pressure is seen to decrease with simultaneous increase in $\mathrm{RH}$ and decrease of temperature. Pressure decrease of the order of $0.5 \mathrm{hPa}$ is indicative of an updraft. It can be seen that the variations seen in all the three parameters occur at a time starting 12:26 $\mathrm{h}$ and ending at 13:36 $\mathrm{h}$. The peak of the activity of all the three parameters occur at the same time namely at 13:06 $\mathrm{h}$. Hence the phenomenon as seen from the variations of $\mathrm{AT}, \mathrm{RH}$ and pressure can be deduced to indicate arrival of cold humid air from below the station. In other words the weather station is situated in the passageway of an updraft that has formed at that time as indicated by the data.

\subsubsection{Changes in Wind Speed and Wind Direction Corresponding to the Detected Updraft}

At the time the updraft happens the wind speed (WS) is seen to decrease to about $0.1 \mathrm{~m} / \mathrm{s}$. Also the wind direction (WD) changes slowly from $175^{\circ}$ to $30^{\circ}$. The data are shown in Fig. (4).

The pattern or way the WD and WS change is at the same time of AT and RH changes. Since the updraft is an event which is either driven by or causes a depression of $0.5 \mathrm{hPa}$ we may accept it as a relatively strong one. It seems that this updraft is much stronger than the speed of horizontal wind that prevailed before $12: 36 \mathrm{~h}$ and so the WS record registered a decrease in a similar pattern as AT, RH \& $P$. The speed of updraft can be 1 to $10 \mathrm{~ms}^{-1}$ according to
Houze $\mathrm{Jr}[6]$ and according to Moore and Vonnegut [12] it can be 4 to $6 \mathrm{~ms}^{-1}$ with a maximum greater than $10 \mathrm{~ms}^{-1}$. The data in Fig. (4) show that WS was only $1.5 \mathrm{~ms}^{-1}$ before the updraft started and so it is not surprising that WS registered a sharp decrease during the updraft. Regarding WD, the weather station was located in, what can be called, a fold on the western side of Western Ghats. The width of the fold is about $500 \mathrm{~m}$ and the depth is about $1 \mathrm{~km}$. The direction of entrance into the fold is almost northerly. That is, wind entering the fold will register a direction of close to $0^{\circ}$. On the opposite side of the weather station, that is on the southern and eastern sides, the terrain slopes up from a distance of about $500 \mathrm{~m}$ from the weather sensors. Therefore during an updraft as seen in the data of Fig. (3) the air mass that arrives at that place from below can register the direction of the fold which is near $0^{\circ}$. Deflection or turning of updraft inside the fold before reaching the wind vane also may be considered. However in the present case the registered WD during the updraft is seen to be $30^{\circ}$.

\subsubsection{Features of the Updraft}

Hence the data of the six weather parameters indicate an updraft happening at a time centred around 13:06 h. The air seems to be arriving from the western side of Western Ghats. The RH is seen to increase from $57.5 \%$ to $80 \%$. This fast rising humid air can be expected to saturate in the close upper layers of atmosphere over Braemore.

Hence the data indicate that possibly the weather station is situated in a region where instability is occurring with involvement of air mass at surface level at the station location. The station is on a mountain slope and orographic lifting can lead to cumulus and $\mathrm{Cb}$ formation as mentioned by [6]. A change in pressure is not indicative of a very localised air movement. For example heating by solar radiation in the morning every day is not detected in a pressure record. Similarly gusts of wind or even slightly strong winds do not show a change in pressure record of $0.1 \mathrm{hPa}$ resolution. The magnitude and interval of reduction in $\mathrm{P}$ indicates that the updraft is most probably a relatively strong one involving quite a large area of several square kilometers and the weather station detected it as it is located inside this area. Therefore the quantity of water vapour that gets lifted by the phenomenon can be quite significant. Hence the data indicate that a strong updraft exists which could have had a span of a few $\mathrm{km}^{2}$ or more transporting considerable amount of water vapour for a period of about 70 minutes in the mountain slope. At this altitude the humidity maximum registered is about $80 \%$. Considering
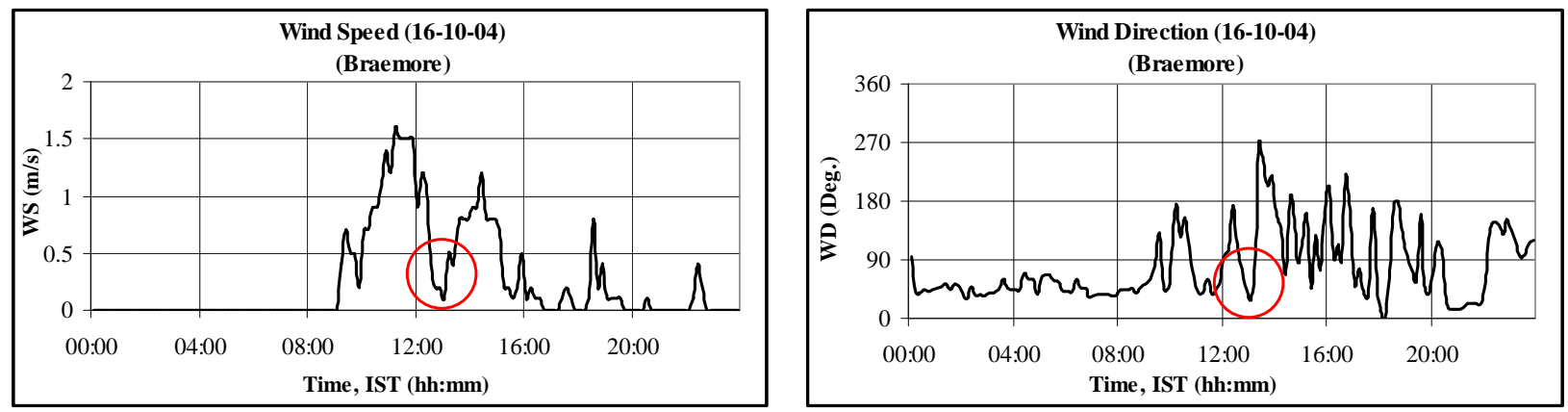

Fig. (4). Changes in WS and WD during updraft detected by the data shown in Fig. (3). 
that the updraft is strong it is possible that the instability or updraft may rise to several hundred meters above the level of the present measurement station. Therefore this lifting could result in formation of a cumulus cloud a few hundred meters above the field station.

\subsubsection{Lightning Detection Subsequent to the Updraft}

The cumulus seems to have formed and grown into a $\mathrm{Cb}$ because there was lightning detected by the lightning detector from 15:00 h. This was close to the station. That is, 84 minutes after the updraft was detected there was lightning. It cannot be said for sure that the variations or the possible instability detected by the variations in weather elements at the surface was the cause of the thunderstorm. But instability existed in the region prior to $15: 00 \mathrm{~h}$ for the convective thunderstorm to form. Under that condition it is possible that the updraft detected in the weather data of the region 84 minutes prior to the thunderstorm is a sample of the instability. There was rain from about $15: 30 \mathrm{~h}$ as seen from the RF data of Fig. (3). In Fig. (5) is shown the lightning detector display for $16 / 10 / 2004$.
The detector is at the centre and black dots represent the lightning discharges. The display at the time of $18: 13 \mathrm{~h}$ shows the spatial distribution of thunderstorm activity for the past ninety minutes. The thunderstorm activity seems to have had a span of about $75 \mathrm{~km}$ in a direction of $135^{\circ}$ to the azimuth which is also the angle of the Western Ghats to the azimuth. It is possible that the instability or updraft which led to the formation of thunder storm in the present case was one covering a large area of $75 \mathrm{~km}$ in length. The angle of the lightning incidence corridor and proximity of it to the mountain range can be taken as an indication of the possible involvement of the Western Ghats mountains in forming the thunderstorm.

\subsubsection{Characteristics of the Weather at the Mountain Location Inferred from Repeated Observations}

Hence the data presented above show existence of strong updraft possibly over a few $\mathrm{km}^{2}$ followed by lightning and rain some time later. Similar weather data showing strong updrafts followed by lightning and rain were obtained from Braemore for a large number of convective thunderstorm activities during the study period of three years.

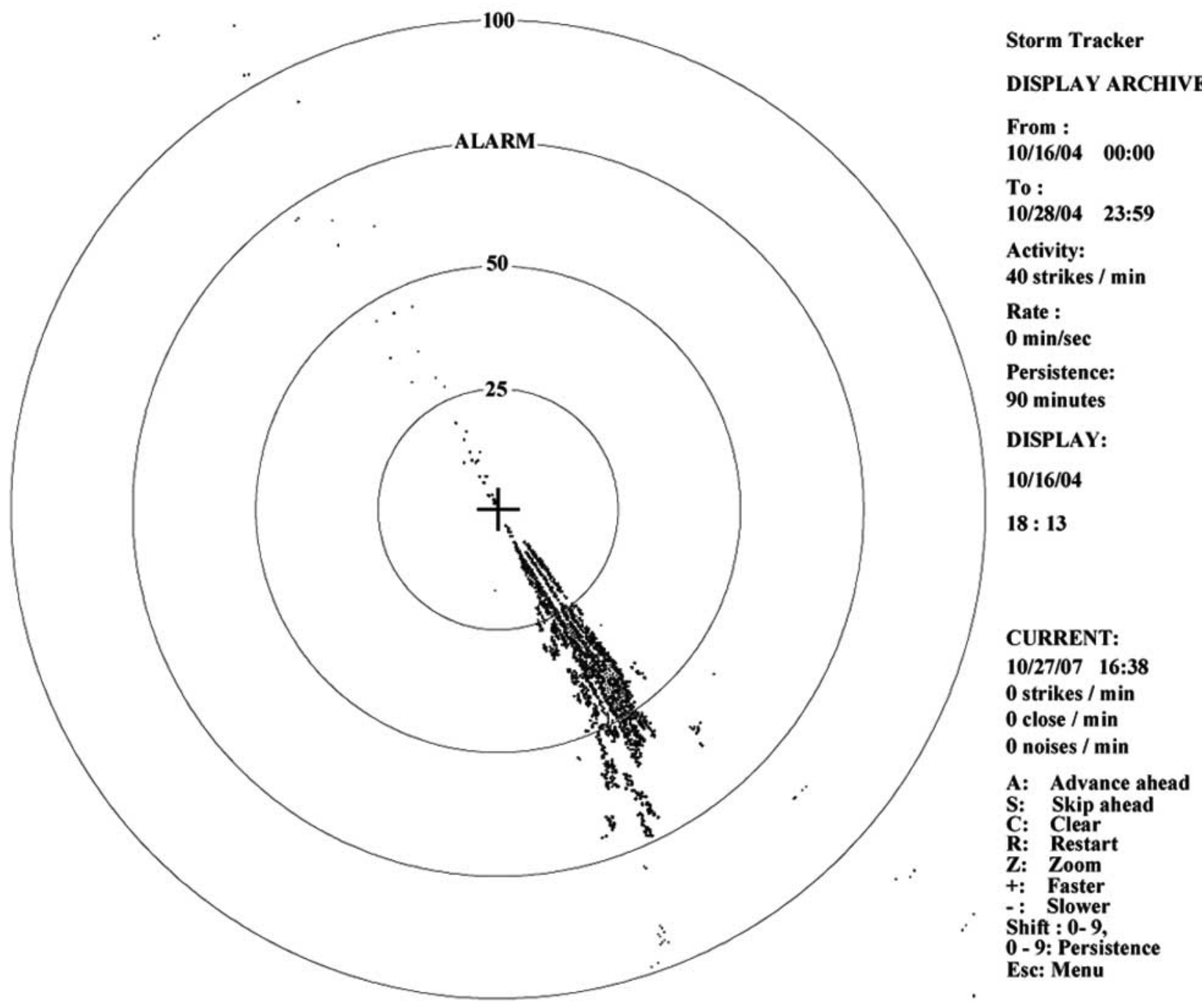

Fig. (5). Lightning detector display at $18: 13 \mathrm{~h}$ on 16/10/04 showing thunderstorm activity for the past 90 minutes. Each dot indicates a lightning discharge event. 

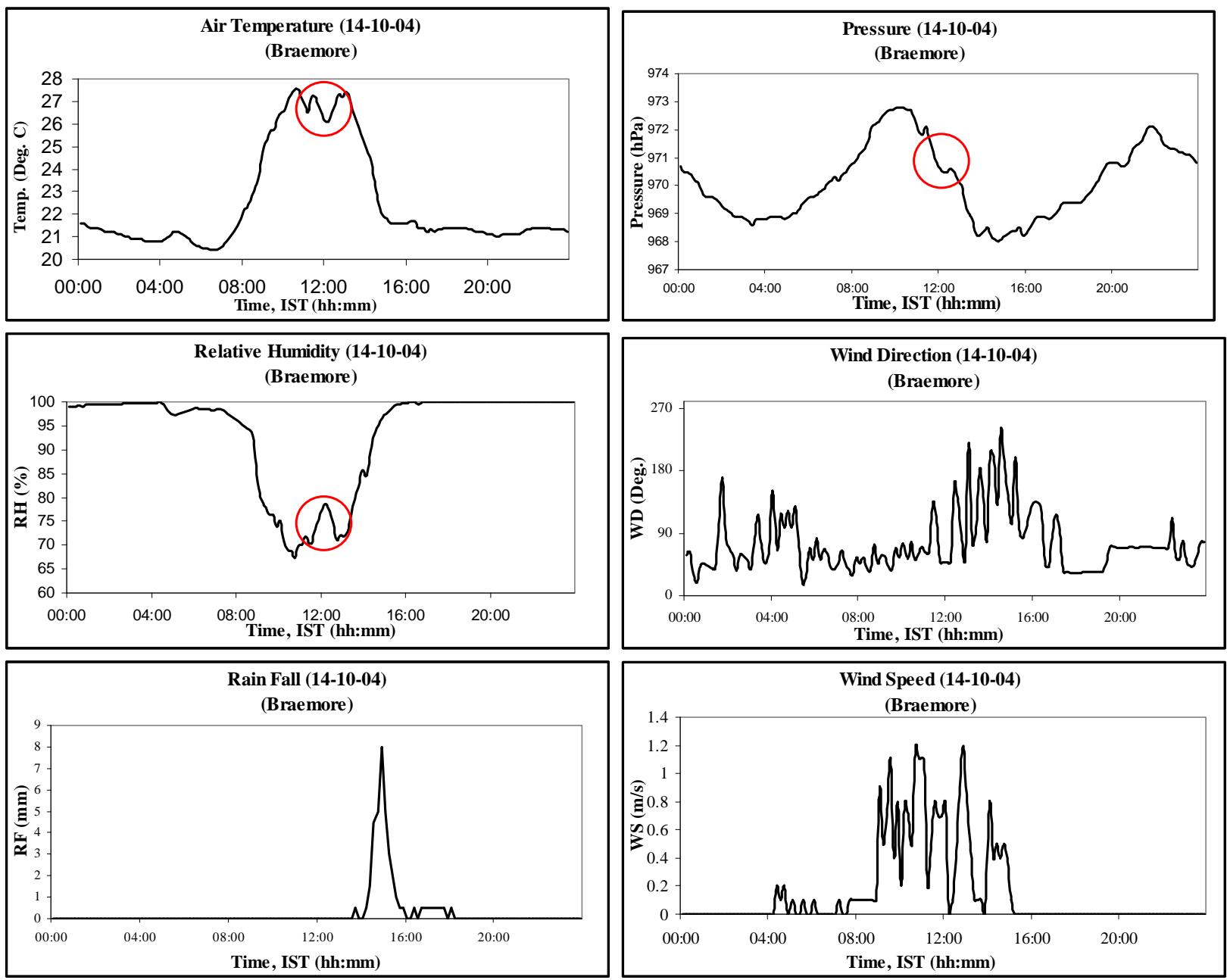

Fig. (6). Braemore weather station data for the day 14/10/04. The circles indicate the simultaneous changes in AT, P and RH during an updraft.

Shown in Fig. (6) is the data from Braemore for $14 / 10 / 2004$, plotted as graphs.

Here also an updraft as indicated by pressure decrease can be seen. In this case the minimum of the P decrease occurs at 12:16 h. However the decrease in pressure is not clear as that in Fig. (3). The decrease is riding on the normal diurnal change in pressure and the magnitude of decrease is less than $0.5 \mathrm{hPa}$. But it can be seen very clearly that AT decreases and $\mathrm{RH}$ increases at the same time and for the same duration as the $\mathrm{P}$ change. $\mathrm{RH}$ changes from $71 \%$ to reach a maximum of $78.6 \%$ at $12: 16 \mathrm{~h}$ and the AT decreases by $1.3^{\circ} \mathrm{C}$ to reach a minimum of $26.2^{\circ} \mathrm{C}$ also at $12: 16 \mathrm{~h}$. WS also can be seen to decrease at the same time. Simultaneously the WD can be seen to go to a direction of about $30^{\circ}$. The decrease in $\mathrm{P}$ and corresponding changes in AT, RH, WD and WS seen in the data of 14/10/04 are possibly changes in weather elements at the surface related to an instability or updraft. Similar depressions or updraft with increase in $\mathrm{RH}$ are seen almost on all days from October to next May in Braemore. A few examples are shown in the succeeding graphs in Figs. $(7,8)$ where a few patterns of variations in $\mathrm{P}, \mathrm{AT}$ and $\mathrm{RH}$ during an updraft on two thunderstorm days can be seen. There was lightning at
17:30 $\mathrm{h}$ in the Braemore area on 10/4/06. In Figs. (7, 8) RH is seen to not reach $100 \%$ during night time. This was a calibration error in the maximum value. A linear shift in the maximum value of $\mathrm{RH}$ need not affect the pattern of variation as it is a function. The data also show that the pattern of variation is not affected.

Summing up, the arrival of cold humid air at the station is the cause of AT decrease. This is different from the normal weather data showing inverse variations in AT and RH. Hence it is clear that AT, RH and P data indicate the occurrence of updraft.

\subsubsection{Deviations from Distinctive Data}

One aspect to be pointed out is that the depressions are not always as conspicuous as seen in the graphs already shown. A few sets of data are presented in figures from Figs. (9-12) where the depressions are not conspicuous but have resulted in strong and long duration updrafts.

The pressure graph in Fig. (9) has a depression indicated by a change in slope near to 13:00 h, but is not conspicuous. By checking the AT and RH data for the times of change of slope it was confirmed that it is a depression and not a noise in the P data. The RH can be seen to increase significantly 

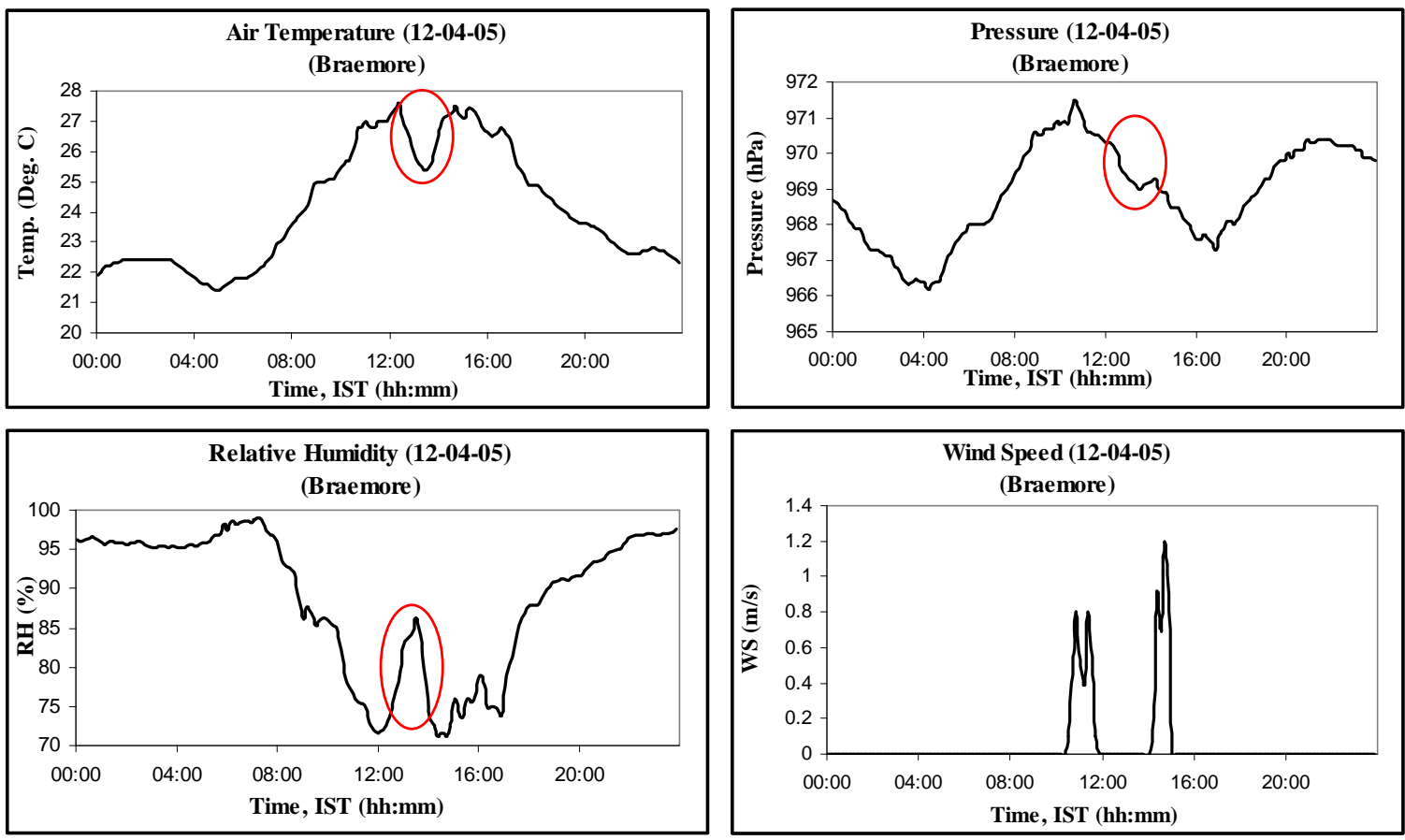

Fig. (7). Data corresponding to a strong updraft on 12/4/05 which was a thunderstorm day. Ellipse markers are used for noting the simultaneous changes.
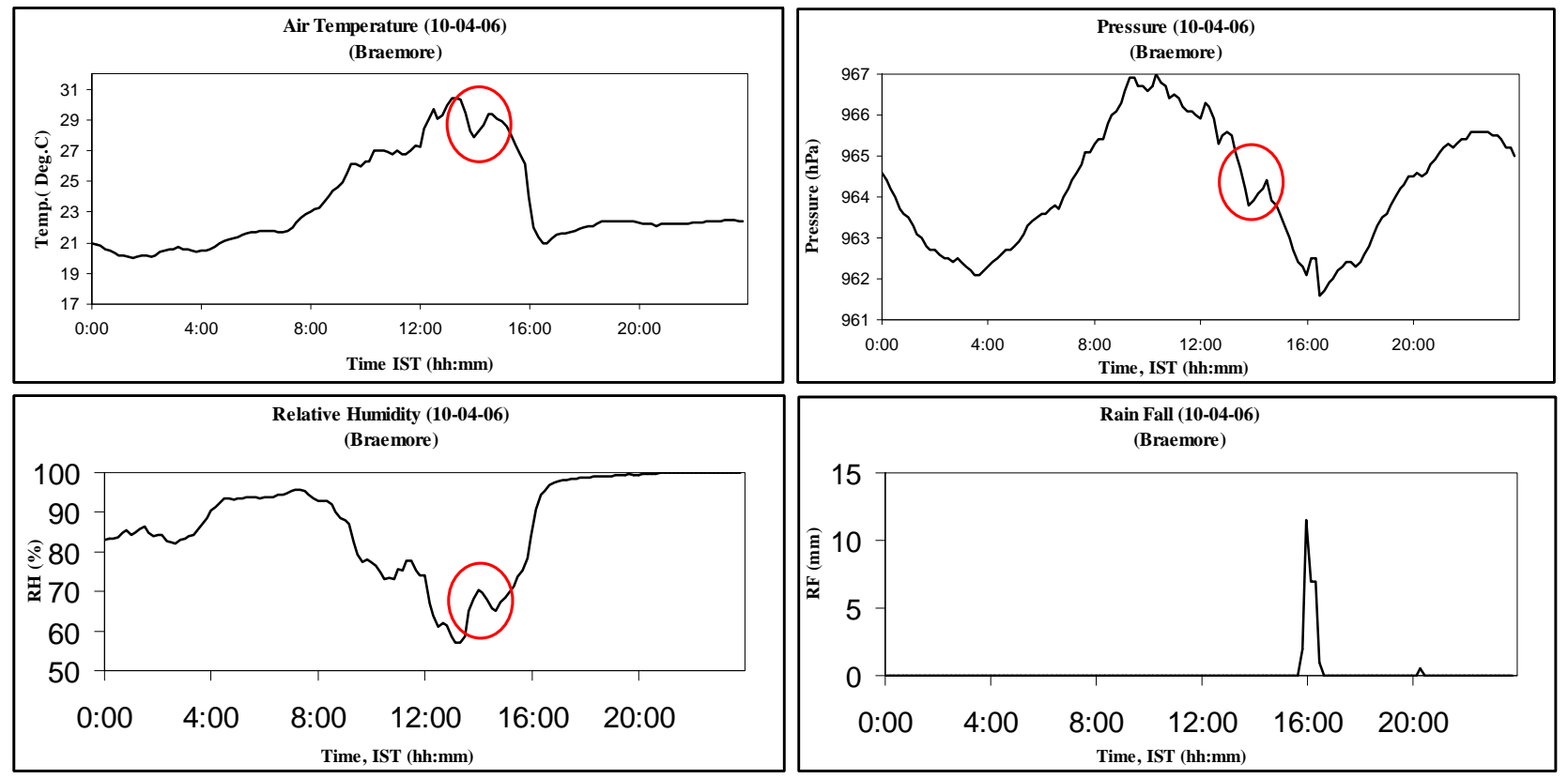

Fig. (8). Indications of updraft on a thunderstorm day in April 2006. Circular markers indicate simultaneous changes.

during the period marked by the rectangular marker in Fig. (9). The AT reduction was about $0.4^{\circ} \mathrm{C}$ and $\mathrm{RH}$ increase was about $12 \%$. There was lightning in the region at 17:00 h. A small kink of about $0.1 \mathrm{hPa}$ can be noticed in Fig. (9) at about 00:32 h. This was due to atmosphere effect. In Fig. (10) is shown another depression on $5^{\text {th }}$ April 2005. In fact, on $5^{\text {th }}$ April there were many instances of updraft. The one indicated by a rectangular marker in Fig. (10) was actually a long duration one lasting 2 hours and 20 minutes. Here also the exact time of initiation of depression was detected by noticing the time of increase of $\mathrm{RH}$. 


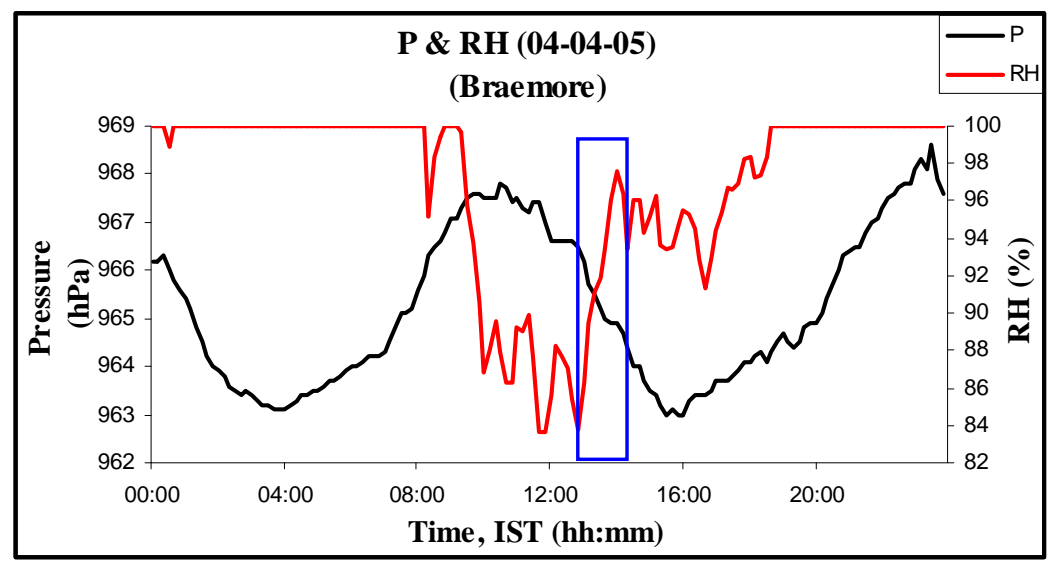

Fig. (9). P and RH variation at Braemore on $4^{\text {th }}$ April 2005. One of the updrafts is between the left and right edges of the rectangular marker.

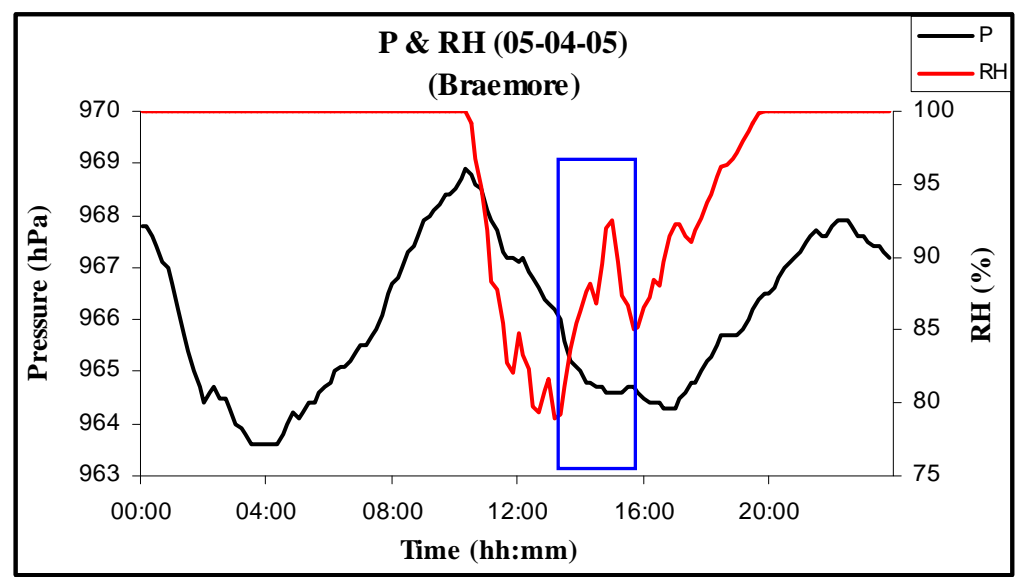

Fig. (10). $\mathrm{P}$ and $\mathrm{RH}$ variation at Braemore on $5^{\text {th }}$ April 2005 which was a thunder storm day. A rectangular marker indicates the not so conspicuous depression and a corresponding significant change in RH.

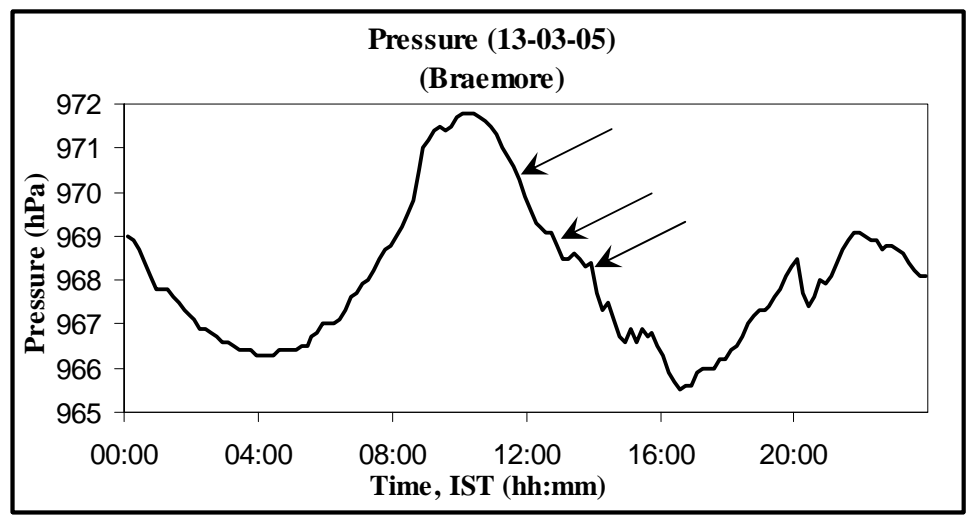

Fig. (11). Pressure variations at Braemore on $13^{\text {th }}$ March 2005 which was a thunder storm day.

Another updraft event on 13/3/05 is shown in Fig. (11). The updraft started at 11:47 h shown by the top arrow and resulted in an increase in $\mathrm{RH}$ by $8.1 \%$. The AT reduction corresponding to this was $0.5^{\circ} \mathrm{C}$. The updraft after a pause at the time shown by the second arrow continued till 13:57 h shown by the third arrow. The maximum increase in $\mathrm{RH}$ during the whole updraft was $14.3 \%$ and AT decrease remained at $0.5^{\circ} \mathrm{C}$. The time of initiation of this updraft also could be detected only after observing the AT and RH data.

Shown in Fig. (12) is another strong updraft. The updraft lasted for 3 hours from 11:25 h. RH and P of the same day are plotted on the same graph and presented in Fig. (13) for clarity. The data of Fig. (13) show how a seemingly small change of slope in $\mathrm{P}$ actually corresponds to a strong updraft. 


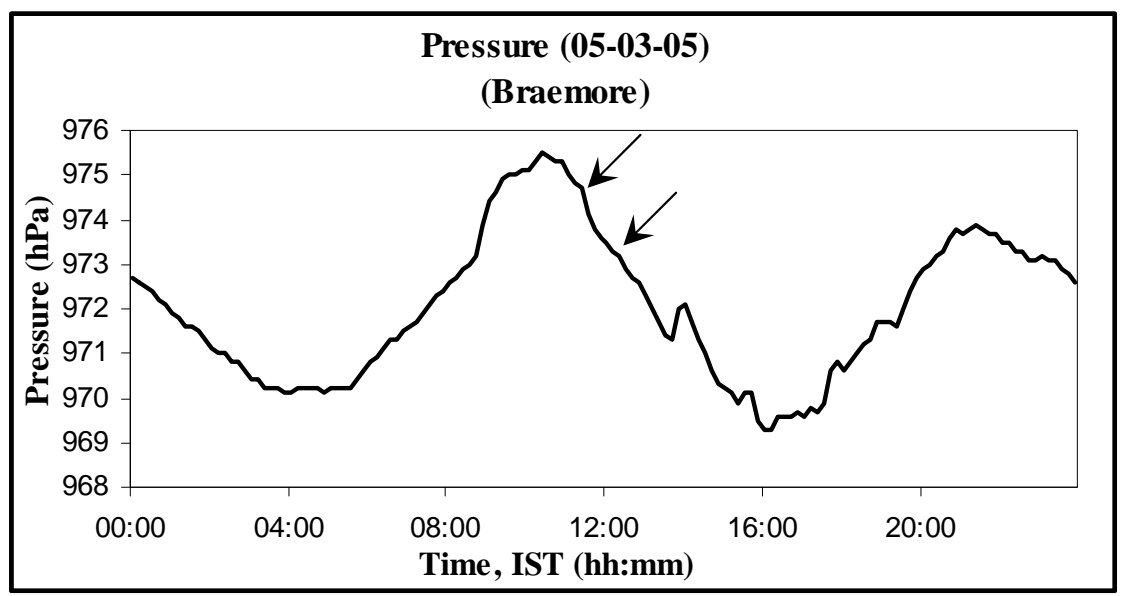

Fig. (12). Indication of updraft in pressure data of $5^{\text {th }}$ March 2005. Arrows mark the beginning and end of a depression.

At the end of the depression the change in $\mathrm{P}$ is about $1 \mathrm{hPa}$ and the increase in $\mathrm{RH}$ corresponding to the depression is close to $20 \%$. Since the change in $\mathrm{P}$ is $1 \mathrm{hPa}$ this depression is termed a strong one.

In fact what is to be observed in the $\mathrm{P}$ data for detecting an updraft is a deviation from a standard pattern. The standard pattern is the well known pressure variation which is easily seen in low latitudes [13]. The important point is that, a departure from the known $\mathrm{P}$ variation should be seen in conjunction with the $\mathrm{RH}$ and AT variation to ascertain an updraft.

From the data collected from Braemore the updrafts seem to be a regular weather feature on the western side of Western Ghats. They occur intermittently and most of them have a time scale of the order of an hour. As mentioned earlier the updrafts seem to be occurring in an area covering a few square kilometers. The degree of reduction in $\mathrm{RH}$ and order of increase in AT observed during these updrafts is a significant short term change in weather. These updrafts occur only during day time from about 10:00 $\mathrm{h}$ to about 18:00 h. Strong and long duration updrafts are seen to cause significant changes in WS and WD data also. These updrafts happen mostly on thunderstorm days. But it is not necessary that detection of an updraft has to end with a thunderstorm. For example $5^{\text {th }}$ March 2005, the data of which are shown in Fig. (13), was not a thunderstorm day.

\subsubsection{Absence of Updrafts when Larger Weather Systems are Present}

These instabilities or updrafts do not seem to occur on days when larger weather systems are active in the area. On most of the days during the south west monsoon season the Braemore station has recorded no updraft. South West monsoon is a well known very large scale weather system active in the Indian region from June to September every

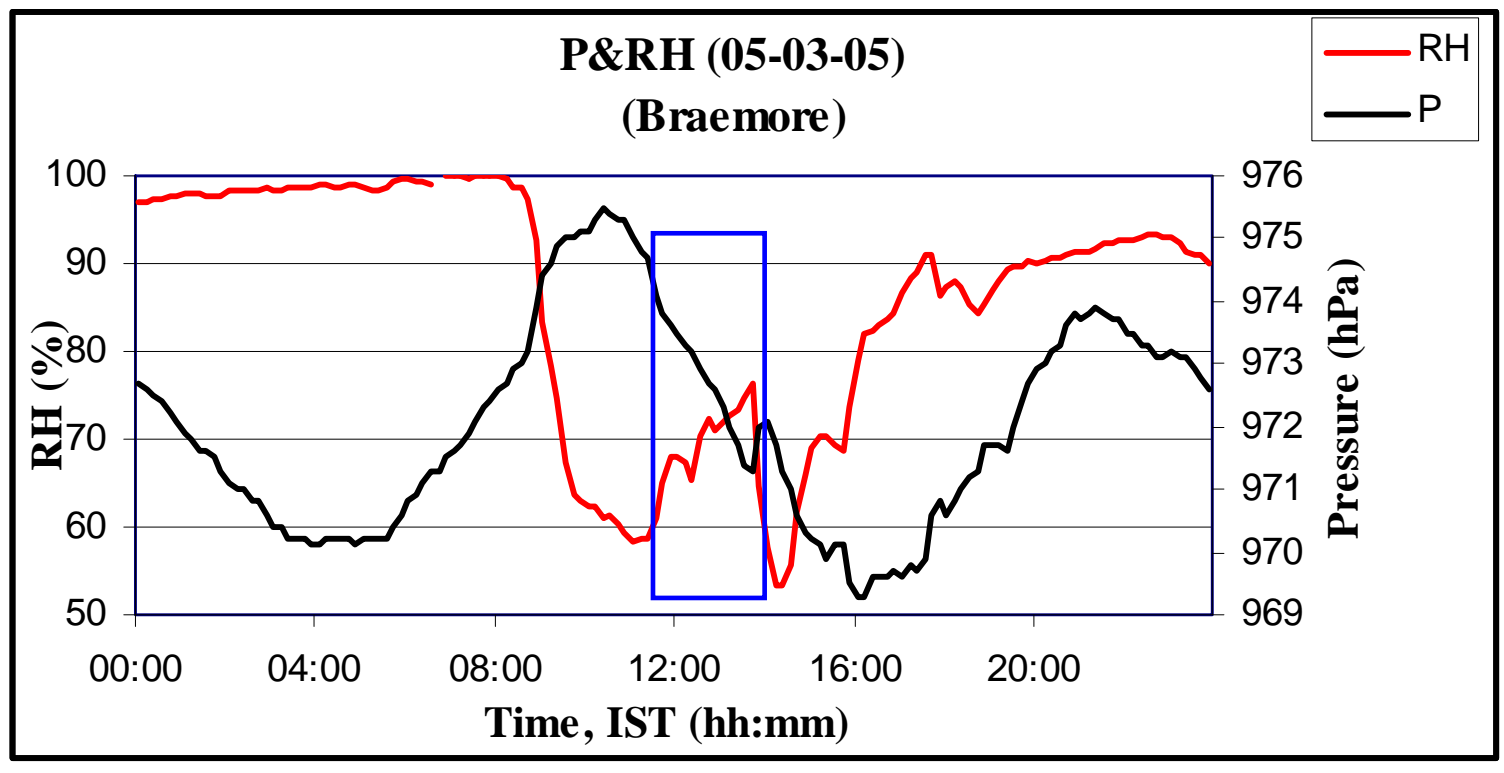

Fig. (13). $\mathrm{P}$ and $\mathrm{RH}$ changes during a strong updraft event. The rectangular marker indicates the seemingly small change in $\mathrm{P}$ and simultaneous significant increase in RH. 

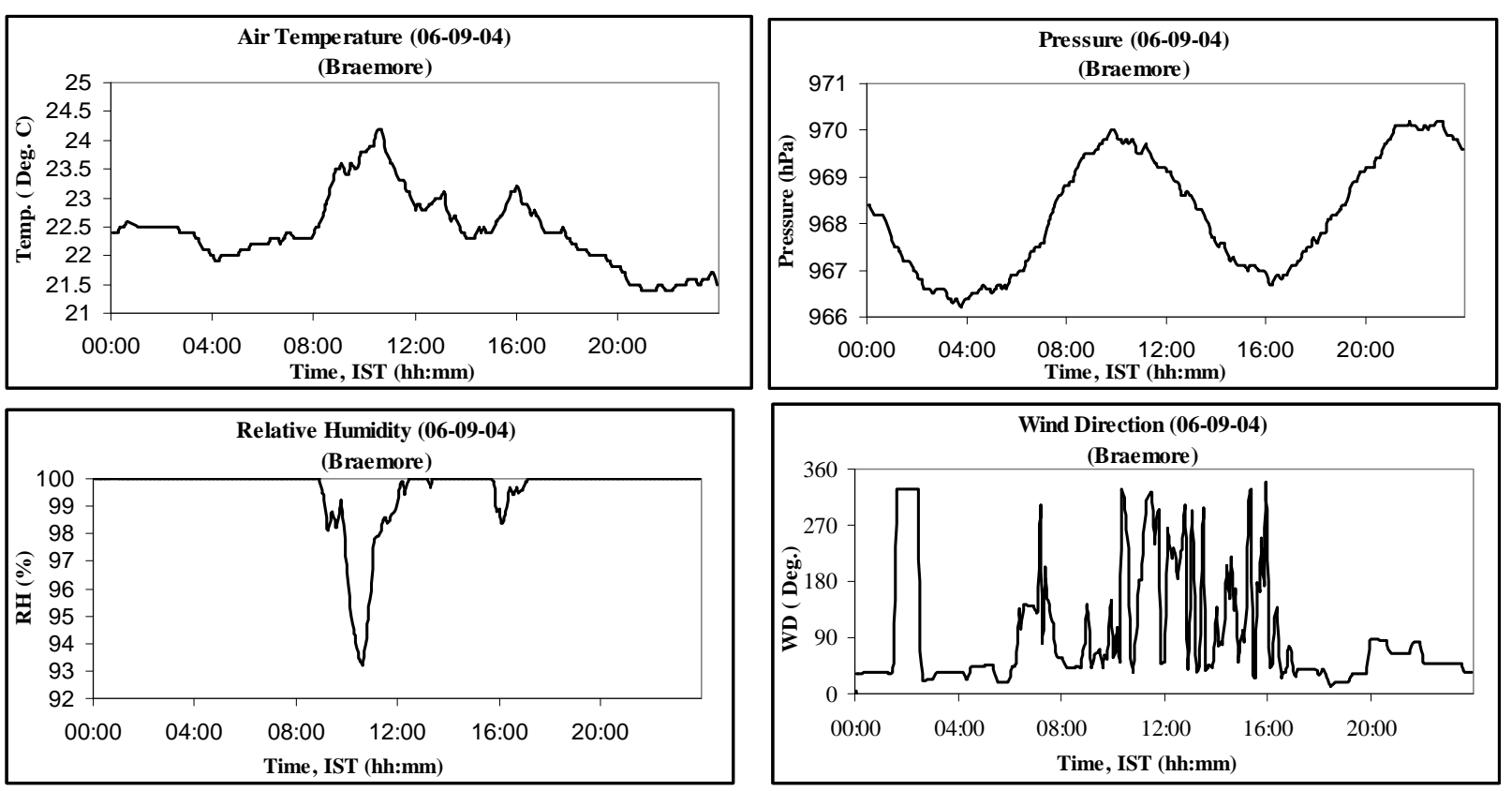

Fig. (14). Weather station data from Braemore for the day of $6^{\text {th }}$ September 2004, a day during the south west monsoon season.

year. Data of such a day are presented in Fig. (14).

The data are of the month of September 2004 when the south west monsoon season has not receded from the Indian peninsula. It can be seen that the day was essentially a rainy day. Solar heating in the morning was less as indicated by the temperature data. AT shows a total change of about $2.5^{\circ} \mathrm{C}$ only. Similarly the $\mathrm{RH}$ also registers a total change of only $7 \%$ due to solar heating. The pressure curve shows a relatively smooth diurnal variation. This possibly indicates that the conditions conducive for formation of an updraft or instability do not occur on these days of south west monsoon. This is not surprising as it is known that lightning incidence in Kerala is minimal during the months of South West monsoon [3].

\subsubsection{Comparison with Weather Data from a Coastal Station}

For ascertaining that the updrafts mentioned above is present only near mountains, data from a coastal station namely the one working at Thiruvananthapuram in Centre for Earth Science Studies (CESS) (Lat.: $8^{\circ} 31^{\prime}$, Long.: $76^{\circ}$ 54 ') were studied. The station is located $40 \mathrm{~km}$ south west of Braemore and is at an altitude of $27 \mathrm{~m}$ AMSL. Location of this station is also shown in Fig. (1). The weather station at CESS was supplied by the same manufacturer as the one at Braemore and was exactly similar in all respects. One striking difference seen in the data from CESS is the smoothness in the diurnal variation of atmospheric pressure. In other words there are no updrafts or depressions seen in the pressure data from the coastal station. The RH and AT data also do not show large fluctuations.

Shown in Fig. (15) is the weather data on 05/04/06 at the coastal station while Fig. (16) show the data for the same day from Braemore.
In other words the CESS weather data do not show sign of any updraft or any event which can be related to formation of a $\mathrm{Cb}$ or a cumulus in the RH and AT data. The $\mathrm{P}$ data shows a smooth variation compared to that from Braemore on thunderstorm days. This is the case of weather data from CESS on most of the days irrespective of whether it is a thunderstorm day or not. In connection with another investigation weather data at 5 minutes and 10 minutes intervals were collected at CESS for three years from 2000 to 2003. This data also do not show any sign of updrafts. However, on many days the CESS weather data have shown atmosphere effect indicating that the weather station is also capable of detecting updrafts related to instabilities, if there were any.

\subsubsection{Segregation of an Updraft Event from Normal Pressure Variation}

One of the normal things to try in the above situation of detecting an updraft would be to isolate the updraft pattern from the basic diurnal variation. That is an operation to remove the low frequency normal diurnal variation from the total pattern to get the high frequency depression variation in $\mathrm{P}$ has to be done. A preliminary attempt showed that the signal and noise are not easily decipherable after filtering the diurnal pattern. For example the slope change in the pressure curve seen at about 19:00 $\mathrm{h}$ in the data shown in Fig. (3) were seen magnified in the filtered data. In addition near 16:00 $\mathrm{h}$ there was another negative going pulse with amplitude almost equal to the depression between 12:26 h and 13:36 h. Both of them are noise when the depression relative to AT decrease and RH increase are considered. The result of segregation of normal pattern is not surprising because the operation carried out is similar to introduction of a high pass filter to the data. Such an operation can magnify the noise present in the pressure curve and so is not useful in detecting updrafts. The right method for segregation would 

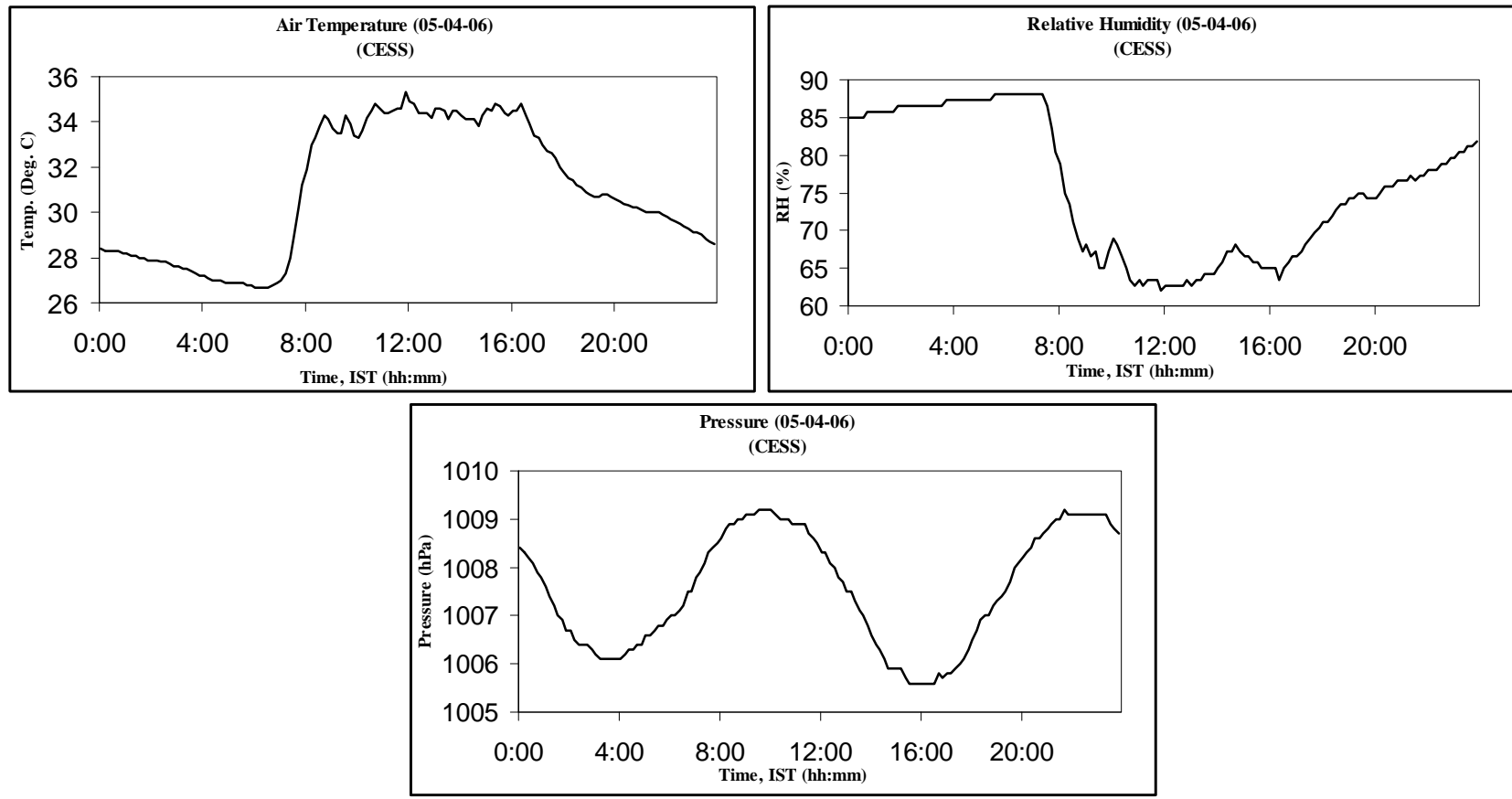

Fig. (15). Graphs of weather elements monitored at the CESS station on 05/04/06.
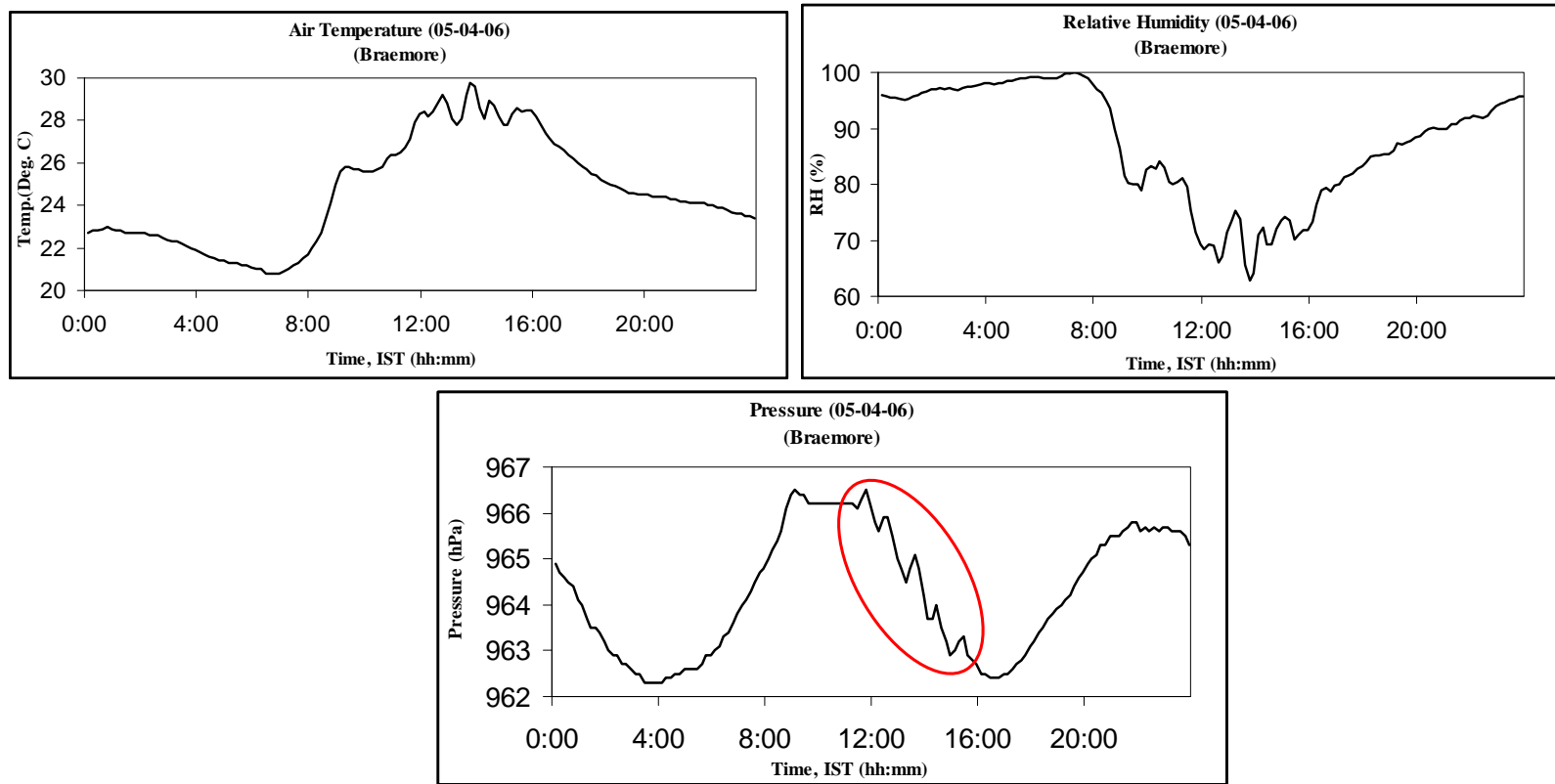

Fig. (16). Graphs of weather elements monitored at Braemore on 05/04/06 showing several updrafts between 1200h and 1600h. The elliptical marker is used to indicate several updraft events.

be to use a software which can compute the changes in slopes of P, RH and AT to separate out the data at times when all the three change in the way as presented in this paper.

\section{CONCLUSIONS}

The study and results presented here show that analysis of finer resolution data on interrelated variations of weather parameters can reflect changes corresponding to an 
instability or updraft at a mountain station like Braemore. One important aspect is that sampling of data at 10 minutes period or less is essential. The detection of frequent occurrence of instability followed by thunderstorm later on most of the thunderstorm days answers to a large extent the question regarding the cause for relatively high lightning in Kerala. The relative reduction in lightning incidents to the west of Palakkad gap and on mountain tops has the value of a confirmatory evidence of this hypothesis.

An updraft detected in the way presented here has the value as an indicator of possible development of a convective thundercloud. Since changes in weather elements is one of the earliest of activities leading to convective thundercloud formation, detection of updrafts in a way as presented here may be useful for examining in real time the $\mathrm{AT}, \mathrm{RH}$ and $\mathrm{P}$ data from weather stations in the region for detection of possible thunderstorm development. A few stations set up on the mountain slope of the Western Ghats and similar mountains where convective thunder storms form could aid in detecting updrafts with its spatial extent. Once updrafts are detected all other data including the vertical profile of parameters relevant to an instability can be checked for possible thunderstorm development. Weather data collected in a similar or at higher frequency could also be useful in locating regions of cumulus and convective thundercloud formation activity.

\section{ACKNOWLEDGEMENTS}

The authors are thankful to the Centre for Earth Science Studies for the financial support to this project. The authors are thankful to the Director, CESS for his kind cooperation and support. Prof. G.S. Bhat of IISc. Bangalore, India is gratefully thanked for the very fruitful discussions. The authors gratefully thank $\mathrm{M} / \mathrm{s}$ Braemore Estate for allowing operation of our field station in their premises. The cooperation of Sri. T.K. Krishnachandran Nair and Sri. M. Ismail, Technical officers of CESS in running the project is thankfully acknowledged. Sri. M. Ismail requires much more than acknowledgement as he is the person who did thunderstorm day noting.

\section{REFERENCES}

[1] GHCC (NASA). Global distribution of lightning April 1995February 2003 from the observations of NASA instruments, Date accessed: 26 Dec 2005. Available from: www.nasa.gov/centers/god dard/news/topstory/2003/0619lightning.html. [Accessed on 26 Dec 2005].

[2] Das MS, Kumar MG, Sampath S. Understanding lightning accidents to alleviate the hazard, Project report, The Centre for Earth Science Studies, India 2004.

[3] Das MS, Sampath S, Kumar MG. Lightning hazard in Kerala. J Mar Atmos Res 2007; 3(1): 111-7.

[4] Sano T, Tsuboki K. Structure and evolution of a cumulonimbus cloud developed over a mountain slope with the arrival of sea breeze in summer. J Met Soc Japan 2006; 84(4): 613-40.

[5] Roland Stull. Meteorology for Scientists and Engineers. SE, Brooks/Cole, Thomson learning, USA 2000.

[6] Houze Jr Robert A. Cloud Dynamics. Academic Press, California, USA 1993.

[7] Centre for Earth Science Studies (India). Resource Atlas of Kerala, Thiruvananthapuram, India: The Centre 1984.

[8] Mac Gorman R Donald, David Rust W. The Electrical Nature of Storms. Oxford University Press, New York 1998.

[9] Robert FG, Joost BA. Introduction to Atmospheric Physics. Academic Press, New York, USA 1963.

[10] Williams R. Earle. Meteorological aspects of thunderstorms. In: Volland Hans, Ed. Hand book of Atmospheric Electrodynamics Vol 1. CRC Press 1994; pp 27-60.

[11] Magono C. Thunder storms, Elsevier Sci Pub Co., Amsterdam, The Netherlands 1980.

[12] Moore CB, Vonnegut B. The Thundercloud. In: Golde RH. Ed. Lightning. London: Academic Press 1977; pp. 51-93.

[13] Nieuwolt S. Tropical Climatology. John Wily \& Sons, London 1977. 